\title{
A parameterization for flow separation in a river dune development model
}

\author{
A.J. Paarlberg, C.M. Dohmen-Janssen \& S.J.M.H. Hulscher \\ University of Twente, Water Engineering \& Management, Enschede, The Netherlands
}

A.P.P. Termes

HKV Consultants, Lelystad, The Netherlands

\begin{abstract}
To simulate dune development, a model based on the two-dimensional vertical shallow water equations is applied to flume conditions. Realistic bedform behaviour of dunes with gentle slopes is obtained: dunes grow in amplitude, develop into asymmetric features and migrate. Due to a constant eddy viscosity in the model, flow separation cannot be treated explicitly. Therefore, a parameterization for flow separation is proposed, based on flume data. A parameterization is derived for the separating streamline, which is the upper boundary of the flow separation zone, and which can be used as bed level for flow computations. The shape of the flow separation zone is found to be independent of flow conditions, and is related to the height and local bed angle at the separation point, and to the angle of the separating streamline at the reattachment point. The parameterization is in reasonable agreement with flume data.
\end{abstract}

\section{INTRODUCTION}

Accurate predictions of water levels during floods in rivers are essential in order to design an appropriate flood defence system or to determine effects of changes to the river system. Water levels during floods are largely influenced by bed roughness in the main channel of the river, resulting from flow over bedforms on the river bed (e.g. dunes, see Fig. 1). Such dunes develop during floods as a result of the increasing discharge, leading to a roughness with a dynamic character. The roughness due to river dunes is dynamic since (1) the roughness increases and decreases during a flood and (2) the roughness lags the discharge with maximum dune dimensions occurring later than the maximum discharge (e.g. Ten Brinke et al. 1999; Julien et al. 2002).

River dunes cause an increase in hydraulic roughness compared to a situation with flat bed, because they protrude into the flow producing shear stress and turbulence. Due to the interaction between unidirectional flow in rivers, and the sediment transport, sinusoidal bedforms develop into asymmetric dunes with gentle stoss-sides and steep lee-sides, as explained by Exner (see Leliavsky 1955, p. 24-26). The lee-side of a dune may become so steep that the flow cannot follow the bed surface any longer, forming a flow separation zone (Fig. 1). When flow is turbulent and viscous (which is generally the case in rivers, and in the used flume experiments), the flow separates behind steep dunes due to an increasing pressure gradient behind the dune (Chang 1970, Buckles et al. 1984). Avalanching at the lee-side results in a dune with a brinkpoint and a slope at the angle of repose which is about $30^{\circ}$ for sand in rivers. The turbulence (eddies) generated in the socalled flow separation zone slows the flow down. This process is often referred to as form drag and can be regarded as an additional roughness due to dunes. The amount of turbulence (and thus roughness) caused by flow over dunes is strongly related to general flow conditions and the shape and size of the flow separation zone (see e.g. Vanoni and Hwang 1967).

At present, there is still limited knowledge about river dunes and the resulting roughness, let alone about their development during floods. Several researchers proposed methods to predict dune dimensions (e.g. dune length and dune height), based on a range of parameters like flow strength, water depth or sediment size. Part of the proposed methods are empirically based (e.g. Julien and Klaassen 1995; Van Rijn 1984), while others are more theoretically based (e.g. Kennedy 1969; Onda and Hosoda 2004). All these methods are designed to calculate equilibrium dune dimensions in steady, uniform flow. In that case a unique dune height and dune length exist for each specific combination of flow characteristics and sediment properties.

Other researchers tried to include the observed time-lag due to unsteady flow conditions, in their models to predict dune dimensions (e.g. Allen 1976 and 


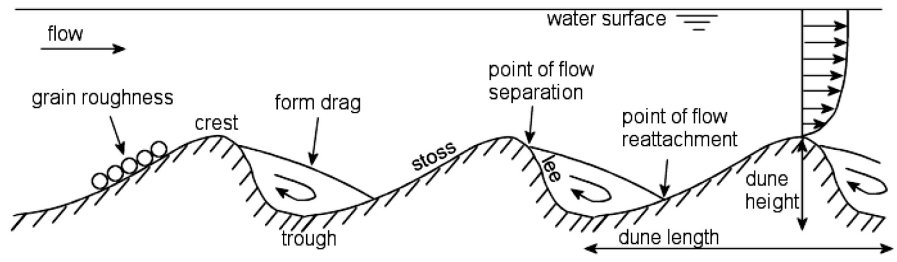

Figure 1. Schematic representation of a dune in streamwise direction, along with some general characteristics.

Fredsøe 1979). However, as shown by Wilbers (2004), none of these predictors is able to predict dune dimensions during several floods in the River Rhine in the Netherlands. Wilbers (2004) developed a calculation method to predict dune development under unsteady flow conditions, based on a method proposed by Allen (1976), in which it is assumed that dunes adapt to equilibrium dune dimensions (as if steady flow conditions were present) with an exponential relationship. Dune steepness and bed shear stress are important parameters in the calculation method and both primary and superimposed secondary dunes can be predicted. Although the calculation method is applied with success to three sections of the Rhine branches, a major drawback is that the method is not generally applicable. For every situation, initial dune dimensions have to be known and data are required to calibrate the adaptation constant. Furthermore, the method gives only limited insight in the physics behind dune development during floods.

In this paper we describe an approach to simulate dune development, which is set up to be appropriate. With this we mean the following. In hydraulic models, the influence of roughness due to dunes is mostly not included. We aim to develop an appropriate prediction method for roughness caused by dunes, which (1) can be included in hydraulic models, (2) and contains no unnecessary details in the modelling.

To start with, we only analyze average dune dimensions in our model, despite the fact that dune development has a strong stochastic behaviour (see e.g. Van der Mark et al. 2005). Further, detailed processes such as vertical sorting (see e.g. Blom and Parker 2004) are not yet included in the model. Our approach is based on the morphodynamic model of Németh (2003), which was developed to predict the evolution of offshore sandwaves. The sandwave behaviour that is predicted by the model, shows large similarities with the development of river dunes: when a unidirectional current is applied, the sandwaves migrate, grow, and become asymmetric. In this paper we test the applicability of this model to predict dune development under flume conditions. Since offshore sandwaves have relatively large dimensions (height of about $10 \mathrm{~m}$ and length of about $500 \mathrm{~m}$ ) flow separation is not likely to occur in offshore conditions. Therefore, this process is not included in the model. However, for river dune development the process of flow separation is very important.

Various methods exist to enable detailed modelling of turbulence in the flow separation zone using direct numerical simulation. For example, Yoon and Patel (1996) adopted a $k-\omega$ turbulence model enabling a detailed computation of the flow in the separation eddy. Results were shown to be in general agreement with the experimental data of Van Mierlo and De Ruiter (1988). Stansby and Zhou (1998) showed that the computation of the flow in the separation zone improved when a non-hydrostatic pressure (instead of hydrostatic) was applied. A disadvantage of such methods is that they are complicated and require much computational effort. To keep the model appropriate, we describe an approach to include flow separation in a parameterized way.

In Section 2 the general model equations are discussed, followed in Section 3 by an analysis of the model, including a dimensional- and a stability analysis. Section 4 discusses the application of the model to dunes with a gentle slope, for which no flow separation occurs. The parameterization of flow separation is described in Section 5. Finally, the conclusions are presented in Section 6.

\section{MODEL}

The model that is used in this study is described in detail in Németh et al. (2002), Németh (2003) and Van den Berg and Van Damme (2005). The model is based on the model developed by Hulscher (1996). In this section the most important equations are mentioned. For the simulations described in the paper, both the numerical implementations of Németh (2003) and Van den Berg and Van Damme (2005) are used. For future research we focus on the latter implementation since this approach is more efficient regarding computational effort and has a more appropriate numerical discretization than the former implementation.

\subsection{Flow model}

The model is based on the two-dimensional vertical (2DV) shallow water equations. The momentum 
equation in $x$-direction (divided by water density $\rho$ ) and the continuity equation read:

$$
\begin{aligned}
& \frac{\partial u}{\partial t}+u \frac{\partial u}{\partial x}+w \frac{\partial u}{\partial z}=-g \frac{\partial \zeta}{\partial x}+\frac{\partial}{\partial z}\left(A_{v} \frac{\partial u}{\partial z}\right) \\
& \frac{\partial u}{\partial x}+\frac{\partial w}{\partial z}=0
\end{aligned}
$$

The velocities in the $x$ - and $z$-directions are $u$ and $w$, respectively. The $z$-coordinate is directed upwards from the average bed, which is located at $z=0$. The mean water depth is denoted by $H$, and the fluctuation in the average water level is denoted by $\zeta$. This results in a total water depth of $H+h+\zeta$, where $h$ is the bottom disturbance on the average flat bottom. Further, $t$ is time, and $g$ and $A_{v}$ denote the acceleration due to gravity and the vertical eddy viscosity, respectively. For more details about the model, the reader is referred to Van den Berg and Van Damme (2005).

\subsection{Boundary conditions}

The boundary conditions at the water surface $(z=H+$ $\zeta$ ) are that there is no flow through the surface, and no shear stress at the surface:

$$
\begin{aligned}
& \frac{\partial \zeta}{\partial t}+u \frac{\partial \zeta}{\partial x}=w \\
& \frac{\partial u}{\partial z}=0
\end{aligned}
$$

The boundary condition at the bed surface is that there is no flow through the boundary:

$$
\frac{\partial h}{\partial t}+u \frac{\partial h}{\partial x}=w
$$

\subsection{Viscosity model and partial slip condition}

An eddy viscosity which is constant over the depth is applied. Since a certain velocity profile is present, this implies that at the bed both the horizontal and vertical velocity are not equal to zero. To allow for a velocity at the bed, but to still impose a friction, a partial slip condition is introduced using the partial slip parameter $S$. The following boundary condition couples the resistance at the bed with the flow velocity at the bed $\left(u_{b}\right)$ :

$$
\tau_{b}=\left.A_{v} \frac{\partial u}{\partial z}\right|_{z=h}=S u_{b}
$$

where $\tau_{b}$ is the bed shear stress. The slip parameter determines the resistance at the bed. When this parameter increases, the bed shear stress increases too. Using this approach, vertical velocity gradients at the bed and the bed shear stress, which is important for sediment transport, are represented correctly. Soulsby (1990) computed velocity profiles using various viscosity profiles over depth and bottom boundary conditions ranging from full slip to no slip. Results show that the velocity profiles vary only little for different settings. We believe this approach is appropriate for our goals.

\subsection{Sediment transport model and bed behaviour}

Only bedload sediment transport is considered in the model, since this is assumed to be the main transport mechanism behind dune development. A general bed load formula according to Komarova and Hulscher (2000) is applied:

$S_{b}=\alpha\left|\tau_{b}\right|^{b}\left[\tau_{b}-\lambda_{1} \frac{\partial h}{\partial x}-\lambda_{2}\left|\tau_{b}\right| \frac{\partial h}{\partial x}\right]$

where $S_{b}$ is the volumetric bed load transport. The proportionality constant $\alpha\left[\mathrm{s}^{2} \mathrm{~m}^{-1}\right]$ and the nonlinearity parameter $b$ describe how efficiently the sand particles are transported by the bed shear stress (Komarova and Huslcher 2000). The parameter $b$ is analytically determined as $0.5[-]$, and $\alpha$ and the slope parameters $\lambda_{1}$ $\left[\mathrm{m}^{2} \mathrm{~s}^{-2}\right]$ and $\lambda_{2}[-]$ are expressed by:

$\alpha=\frac{8 \gamma}{s g}$

$\lambda_{1}=\frac{3 \Theta g(s-1) d}{2 \gamma \tan \left(\phi_{s}\right)} \quad \lambda_{2}=\frac{1}{\tan \left(\phi_{s}\right)}$

where $\Theta$ is the critical Shields parameter modelled by a constant of $0.047, s$ is the relative density of sediment equal to 2.65 and $\gamma$ is equal to 1 for unidirectional river flow. The grain diameter is denoted by $d$ $[\mathrm{mm}]$ and $\phi_{s}$ is the friction angle (the angle of repose) with $\tan \left(\phi_{s}\right)=0.6$ (i.e. $\phi_{s} \approx 30^{\circ}$ ). The scale factors for the bed slope mechanism $\lambda_{1}$ and $\lambda_{2}$ take directly into account that sand is transported more easily downslope than up-slope. The second bed slope factor has a more diffusive character.

Bed evolution follows from sediment continuity:

$\frac{\partial h}{\partial t}=-\frac{\partial S_{b}}{\partial x}$

\section{ANALYSIS OF THE MODEL}

\subsection{Model set-up: parameter settings}

The slip parameter, as well as the eddy viscosity, are parameters which are difficult to estimate. Relationships for offshore conditions are derived by Besio et al. (2003) which depend on hydraulic conditions and the 


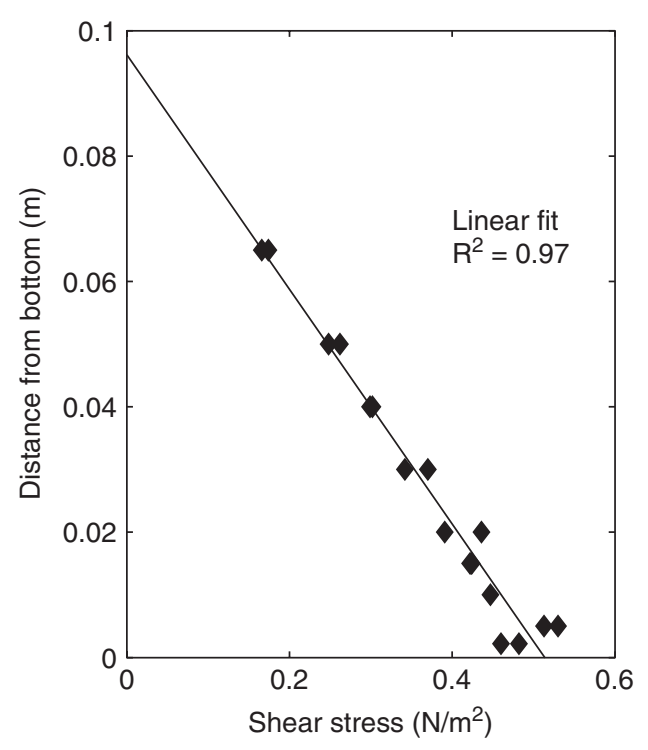

Figure 2. Shear stress distribution over depth in flume experiment T3 of Van Mierlo and De Ruiter (1988).

roughness of the seabed. For flume or river conditions such relationships do not exist. In the model, the slip parameter $S$ and the vertical eddy viscosity $A_{v}$ from Eq. (6) have a direct relation with the velocity profile. Therefore, measurements of velocity profiles over a rough flat bed in flume experiment T3 of Van Mierlo and De Ruiter (1988) are used to calibrate these parameters. In the experiment, the water depth is $10 \mathrm{~cm}$ and the depth-averaged flow velocity is $0.38 \mathrm{~m} / \mathrm{s}$ $(\mathrm{Fr} \approx 0.38)$.

Because of the used partial slip condition at the bottom boundary, no logarithmic velocity profile can be obtained. Therefore, we calibrate on the general shape of the velocity profile and on the value of the bed shear stress (which is important for sediment transport). Measured values of the turbulent $u$ - and $w$ velocities can be used to obtain the measured shear stress distribution over the water column using:

$\tau_{x z}=\rho \overline{u^{\prime} w^{\prime}}$

where the overbar denotes time-averaging (over the turbulent timescale). The shear stress distribution shown in Figure 2 is found. For stationary flow, the shear stress distribution over the depth is linear (see e.g. Jansen et al. 1994). Linear extrapolation to the bed, results in a bed shear stress of $0.51 \mathrm{~N} / \mathrm{m}^{2}$. Calibration against the velocity profile and the bed shear stress results in $S=1.9 \times 10^{-3} \mathrm{~m} / \mathrm{s}$ and $A_{v}=1.9 \times 10^{-4} \mathrm{~m}^{2} / \mathrm{s}$. Figure 3 shows the comparison of the modelled and the measured velocity profile.

The parameters that remain to be estimated are the empirical constants in the sediment transport formula

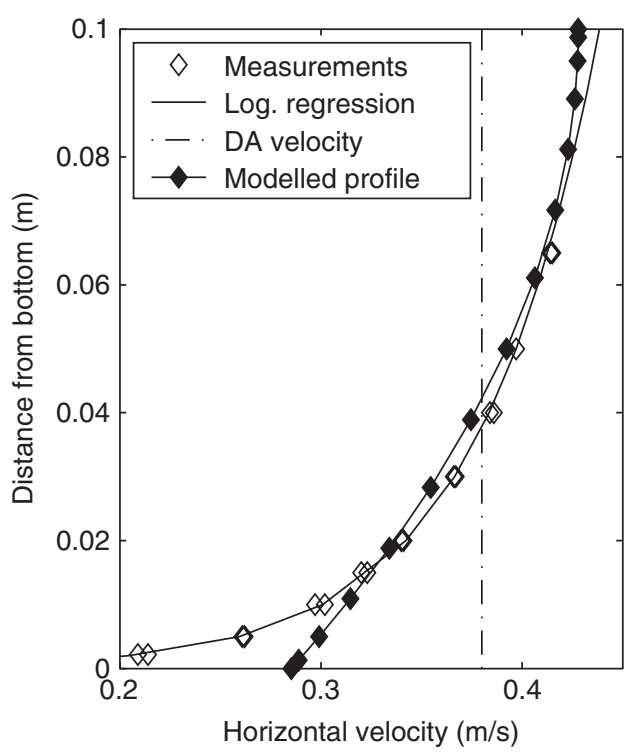

Figure 3. Measured and modelled velocity profile.

(Equation (7)). The proportionality constant $\alpha$ is estimated using Equation (8) at 0.3 . The sediment transport formula is developed to use in offshore conditions, and the exact behaviour of the slope parameters $\lambda_{1}$ and $\lambda_{2}$ under river or flume conditions is not known. Therefore, we choose to include only the slope factor with the most simple form (so $\lambda_{1}$, without bed shear stress dependency) and analyze the results using this approximation. For the grain size a typical value of $3 \mathrm{~mm}$ is used, resulting in $\lambda_{1} \approx 6 \times 10^{-3}$. It should be noted that this parameter will be changed in Section 3.3, after considerations based on a dimensional- and a stability analysis of the model equations.

\subsection{Dimensional analysis}

In this model, flow and sediment transport are decoupled because, in general, changes in the flowfield have a shorter timescale than morphological changes. This aspect is checked by performing a dimensional scaling analysis on the model equations.

Table 1 shows the used scaling parameters. The length scale $\delta$ follows from scaling the momentum equation (1) using the characteristic scaling parameters from the table. Using the characteristic values for the parameters $U, H$ and $A_{v}$ discussed in Section 3.1, this (horizontal) length scale is about 21 meter. A hydrodynamical timescale $\left(T_{H}\right)$ can be derived from introducing the scaling parameters in Equation (3):

$$
T_{H}=\frac{U^{2} H}{A_{v}\left(1-F r^{2}\right)}
$$


Table 1. Scaling of variables.

\begin{tabular}{llll}
\hline Parameter & Symbol & Scale & Dimensions \\
\hline$x$ - coordinate & $x$ & $\delta=\frac{U H^{2}}{A_{v}}$ & $\mathrm{~m}$ \\
$z$ - coordinate & $z$ & $H$ & $\mathrm{~m}$ \\
Hor. velocity & $u$ & $U$ & $\mathrm{~m} / \mathrm{s}$ \\
Vert. velocity & $w$ & $U \frac{H}{\delta}=\frac{A_{v}}{H}$ & $\mathrm{~m} / \mathrm{s}$ \\
Water surface & $\zeta$ & $U^{2} / g$ & $\mathrm{~m}$ \\
Bed shear stress & $\tau$ & $\frac{A_{v} U}{H}$ & $\mathrm{~m}^{2} / \mathrm{s}$ \\
Bed level & $z_{b}$ & $H$ & $\mathrm{~m}$ \\
\hline
\end{tabular}

Similarly, a morphodynamical timescale $\left(T_{M}\right)$ can be deduced from Equation (10) as:

$$
T_{M}=\frac{U H^{3}}{A_{v} \alpha\left(U A_{v} /[H]\right)^{b}}
$$

resulting in the following ratio:

$\frac{T_{M}}{T_{H}}=\frac{U H}{\alpha\left(U A_{v} /[H]\right)^{b}} \frac{\left(1-F r^{2}\right)}{F r^{2}}$

For the parameters previously discussed, it follows that $T_{M} / T_{H} \approx 25$, and for typical river conditions (using same values, but now $H \approx 10 \mathrm{~m}$ ) this gives $T_{M} / T_{H} \approx 2.8 \times 10^{4}$. This makes it acceptable to use a quasi-stationary approach as in the model. It should be noted that the vertical eddy viscosity also changes for a larger water depth (i.e. it probably becomes larger towards the water surface).

\subsection{Stability analysis}

A linear stability analysis gives the growth rate and migration velocity of small initial bed disturbances. The initially fastest growing wave length of bed perturbations is often also a good indication for the bed behaviour on the longer term (see e.g. Van den Berg and Van Damme 2005). Thus the stability analysis can give indications whether the model equations can be applied to flume conditions, and whether realistic migration rates and growth rates are found. Furthermore, the response of the equation to different parameter settings can be investigated. The linear stability analysis is performed both analytically and numerically, to verify the numerical model results.

For the analytical approach, use is made of the method of Van Damme and Van den Berg (2005). A small sine-shaped disturbance of $\epsilon H$ with $\epsilon<<1$ is imposed on the average flat bed. The effect on the flow field is analyzed, which can be used to evaluate sediment transport and bed evolution. Figure 4 shows the time-independent component of the flow solution

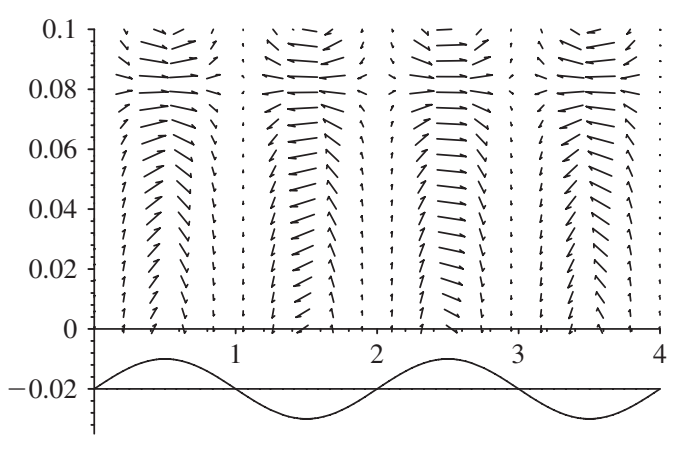

Figure 4. Residual time-independent flow field over two identical dunes (sketched at bottom, not to scale). On the vertical axis is the waterdepth [m], and on the horizontal axis is the distance along the dune [m]. Unidirectional flow is from left to right. Image courtesy: Ruud van Damme.

over a small sine-shaped bed disturbance. The basis instability mechanism is present: sediment is transport uphill. Since unidirectional flow is imposed, we observe an asymmetric of the cells in flow direction. For the numerical stability analysis, the numerical implementation of the model equation of Németh (2003) is used. This numerical calculation method solves the model using Chebyshev polynomials for one solitary dune. Figure 5 shows the results for different values of the parameter $\lambda_{1}$. Also results of the analytical stability analysis are included.

Numerical and analytical computations agree well. A (constant) migration rate of about $10 \mathrm{~m} /$ day is found, and the growth rate ranges between zero and about $10 \mathrm{~m} /$ day. The migration rate is in general agreement (order of magnitude) with measurements in the Rhine (Wilbers 2004) and with flume measurements with floodwaves (Wijbenga and Van Nes 1986). The growth rate seems a little high compared to the same measurement data. In Figure 5, it can be observed that the behaviour is different for different values of the slope parameter $\lambda_{1}$. In Section 3.1, a value of $6 \times 10^{-3}$ for this slope parameter was derived. When this value is used in the stability analysis, no growth is found, and every initial disturbance is flattened out over time. The formula used to derive the value of $\lambda_{1}$ is derived from an analysis for the modelling of offshore sandwaves, while in river situations some important scaling factor are essentially different. From a dimensional analysis of the sediment transport equation used in the model, it follows that $\lambda_{1}$ scales with a factor $A_{v} /(U H) \approx 1 / 200$. Furthermore, in the floodwave flume experiments of Van Mierlo and De Ruiter (1988) the order of magnitude of the observed dune length was about 1 meter. According to Figure 5 this seems to fit with a value of $\lambda_{1}=6 \times 10^{-5}$. Therefore, in the following simulations this value is used. 


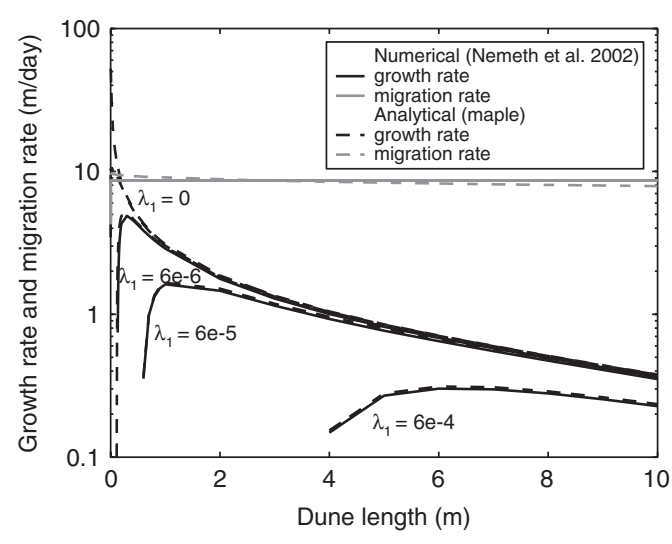

Figure 5. Growth rate and migration rate curves for perturbations with different dune lengths. Negative growth rates are not shown.

\section{DUNES WITH GENTLE LEE SLOPES}

Flow over a cosine shaped dune with a height of $4 \mathrm{~mm}$ and a length of $2 \mathrm{~m}$ is simulated. Initially, the maximum slope of the bed is about $0.18^{\circ}$, so no flow separation is expected (this is expected to occur at an angle of about $10^{\circ}$ ). The average water depth is $10 \mathrm{~cm}$, the depth averaged flow velocity is $0.38 \mathrm{~m} / \mathrm{s}$, and for the slope parameter $\lambda_{1}$ a value of $6 \times 10^{-5}$ is used. Since periodic boundary conditions are used, the bedform length remains constant during the simulations. The initial flow field for steady flow is shown in Figure 6.

Figure 7 shows that the symmetric cosine shape disturbance develops into a more asymmetric profile with a larger dune height and a steeper lee-side. The dunes migrates at a velocity of about 8 meters per day, which is in reasonable agreement with stability analysis and flume and field measurements (e.g. Wijbenga and Van Nes 1986 and Wilbers 2004).

Results are shown only initially because longer simulations fail as a result of numerical method used in this implementation, which is originally developed for the simulation of offshore sandwaves. Sandwaves are more symmetric than river dunes, because they are formed by an oscillatory tidal motion. In the numerical method polynomial fitting of functions is used, and it is difficult to fit a polynomial through an asymmetric function.

\section{DUNES WITH STEEP LEE SLOPES: FLOW SEPARATION}

The numerical method presented in Section 4 does not allow flow separation. Due to the bed boundary condition with partial slip, a constant eddy viscosity over the depth, and a hydrostatic pressure assumption, no flow

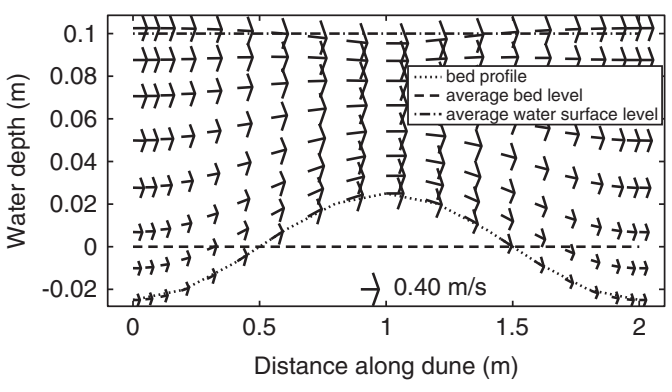

Figure 6. Initial (steady) flow field over a dune with height of $4 \mathrm{~mm}$ and a length of $2 \mathrm{~m}$. Vertical scale is strongly exaggerated with respect to the horizontal scale.

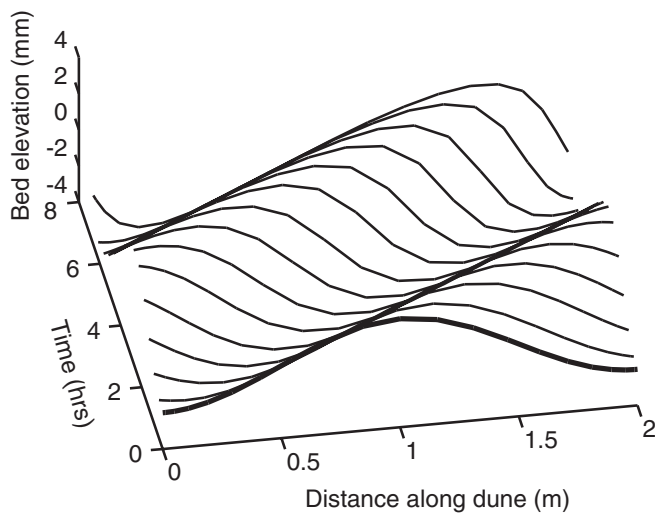

Figure 7. Initial bed evolution of a symmetric dune with a dune height of $4 \mathrm{~mm}$ and dune length of $2 \mathrm{~m}$. Vertical scale is strongly exaggerated with respect to the horizontal scale.

recirculation can occur in the flow field. To model the process of flow separation appropriately, an approach to include flow separation in a parameterized way is discussed.

In this section references are made to flume experiments of various authors. An overview of the general conditions of these experiments can be found in Table 2, with in the first column abbreviations for the different experiments. These abbreviations will be used in the text.

\subsection{Approach and existing parameterizations}

Figure 8 shows the results of a flume experiment of McLean et al. (1999) in which the flow separates over a steep concrete triangular dune. As a result a flow separation zone is formed, with a large eddy present in this zone. The flow separates at a small distance behind the bedform top and the separating streamline reattaches at a certain distance downstream on the stoss-side of the next dune. The formation of the large eddy in the 

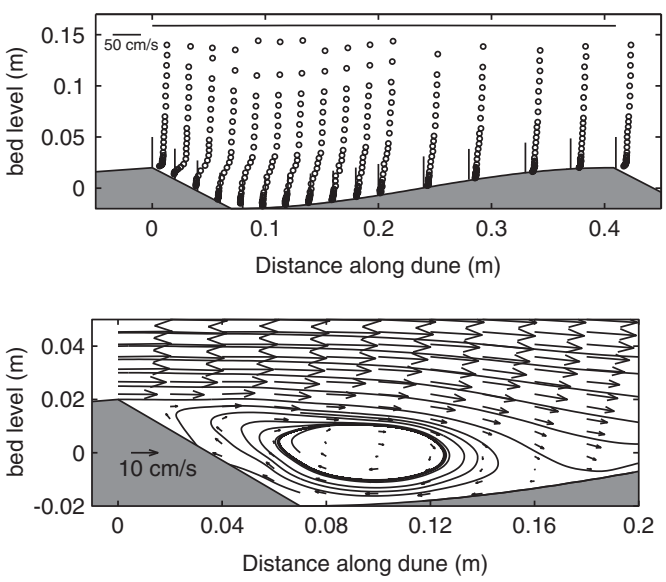

Figure 8. Experiment ML5; top: horizontal velocities; bottom: streamlines with emphasis on the separation zone.

flow separation zone is initiated by the large amount of turbulence at the reattachment point.

The parameterization for flow separation developed in the current paper is based on the work of Kroy et al. (2002). They state that in general dune formation and migration do not depend very sensitively on the details of the complicated process of flow separation. In their model for aeolian dune development, an imaginary bed level is assumed at the boundary of the normal flow and the flow separation zone. This so-called separating streamline is parameterized in a form as simple as possible obeying physically motivated boundary conditions at the flow separation- and reattachment point. The separating streamline is used as bed level for flow computations. So flow details in the flow separation zone are not computed at all. Effectively, their approach is to "cut-off" the region with flow separation from the flow computation. The shear stresses in the flow separation zone are set to zero, since they are typically below threshold for sand transport.

In a sense, this approach is similar to the approach of Niño et al. (2002). In their discrete particle model applied for both aeolian and underwater dune development, the flow separation zone is represented as a shadow zone with no net sediment transport, due to the nature of the recirculating flow characteristics of this zone. With their model they show that the method to parameterize the flow separation zone as a shadow zone agrees reasonably well with measurements for underwater dunes.

Kroy et al. (2002) derive the following function for the separating streamline $(s)$ :

$$
\begin{aligned}
s\left(x_{*}\right)=\left(2 H_{s}+\alpha_{s}^{\prime} H_{s}\right) x_{*}{ }^{3} & -\left(3 H_{s}+2 \alpha_{s}^{\prime} L_{s}\right) x_{*}{ }^{2} \\
& +\alpha_{s}^{\prime} L_{s} x_{*}+H_{s}
\end{aligned}
$$

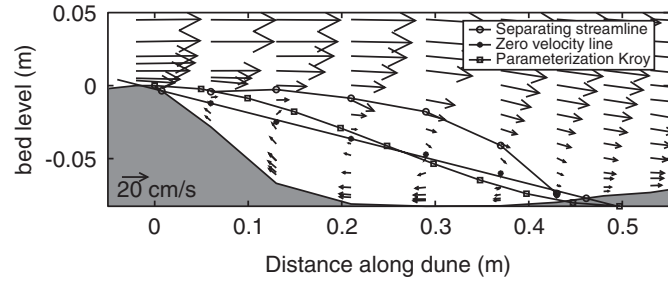

Figure 9. Parameterization of Kroy et al. (2002) compared to flume experiment MR5.

where $H_{S}$ is the height of the bedform at the flow separation point, $\alpha_{s}^{\prime}$ is the local bed angle at the same point, $L_{s}=x_{r}-x_{s}$ the length of the separation zone, where $x_{r}$ is the flow reattachment point, and $x_{*}=\left(x-x_{s}\right) / L_{s} \in[0,1]$. They estimate $L_{s}$ based on a pre-defined maximum slope of the separating streamline $\left(14^{\circ}\right)$. The coefficients of the third order polynomial are determined from boundary conditions at the flow separation- and reattachment point, and ensure a continuous bedform shape. The parameterization of Kroy et al. (2002) is based on computations of air flow over dunes, and is not validated with experimental data.

Figure 9 shows the comparison of the parameterization of Kroy et al. (2002) to experiment MR5 of Van Mierlo and De Ruiter (1988). In the figure a computed separating streamline and the zero velocity line are included (it will be explained later how these lines are determined). It is clear that the separating streamline found with Equation (15) fits the zero velocity line rather than the separating streamline.

Nelson and Smith (1989) extended the model for flow over dunes of McLean and Smith (1986), which is based on boundary layer theory, with the region of flow separation by including the process of flow separation via a parameterization of the separating streamline. The formation of the separation zone influences the wake formation in the total flow field, and the developing nonuniform boundary layer downstream of the reattachment point. In their parameterization they use the ratio of maximum upstream directed velocity to the velocity above the lowest wake. So, the shape of the separating streamline is based on velocity characteristics. Since our model does not reproduce these characteristics, this parameterization will not be analyzed further.

\subsection{Zero velocity line and length of the FSZ}

Wilbers (2004) analyzed a considerable amount of flume data (and to a lesser extent river data) with measurements on velocity profiles over various bedforms that extend into the flow separation zone. The zero velocity line is the line connecting the points of zero velocity in the flow separation zone. This line starts at 
the flow separation point and ends at the reattachment point. Wilbers (2004) showed that the zero velocity line may be a linear function, which has an angle $\left(\alpha_{z v l}\right.$, Fig. 10) of $-10 \pm 1^{\circ}$, independent of bedform type and-dimensions and flow conditions.

In Table 2 an overview of data is given for which the angle of the zero velocity line is analyzed. Partly, the data comprises the same data as used by Wilbers (2004). However, some of the data have become available digitally. Further, some of the data that Wilbers

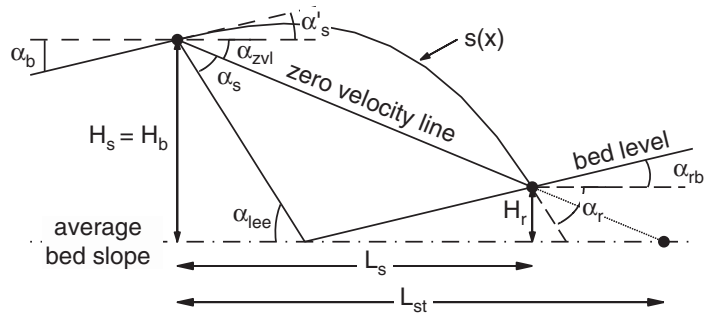

Figure 10. Illustration of the flow separation zone, along with some definitions. Partly after Wilbers (2004). used, are not used, since there were no or too few measurements of the reversed flow near the bottom in the flow separation zone.

The points of zero velocity are found using the method of Wilbers (2004). Linear regression through the points of zero velocity yields a line, which, if it is extrapolated to the bed, gives the points of flow separation- and reattachment. When the angle of the zero velocity line is known, the often used ratio $\gamma=L_{s t} / H_{b}$ can be computed. Here $L_{s t}$ is the total length of the flow separation zone from separation to the crossing-point with the averaged bed level, and $H_{b}$ is the height of the flow separation point, which is assumed at the brinkpoint (Fig. 10). This ratio is shown in Table 3, and the ratio is plotted as a function of the Froude number $(\mathrm{Fr}=U / \sqrt{g H})$ in Figure 11. No clear relation is found between the total length of the flow separation zone and the Froude number. This is in agreement with the statement of Wilbers (2004), that the shape of the flow separation zone is independent of flow characteristics. According to Wilbers (2004), the zero velocity line has an average angle of $-10 \pm 1^{\circ}$ with the average bed slope, not only independent of flow conditions, but also independent of bedform

Table 2. Data used for parameterization of a separating streamline.

\begin{tabular}{|c|c|c|c|c|c|c|c|c|c|c|c|c|}
\hline \multirow{2}{*}{$\begin{array}{l}\text { Author * } \\
\text { Parameter ** }\end{array}$} & \multicolumn{5}{|c|}{ I. Flow conditions } & \multicolumn{7}{|c|}{ II. Bedform specifications } \\
\hline & $\begin{array}{l}\text { fw } \\
{[\mathrm{m}]}\end{array}$ & $\begin{array}{l}\mathrm{H} \\
{[\mathrm{m}]}\end{array}$ & $\begin{array}{l}\mathrm{U} \\
{[\mathrm{m} / \mathrm{s}]}\end{array}$ & $\begin{array}{l}\mathrm{Se} \\
\left(\times 10^{-4}\right)\end{array}$ & $\begin{array}{l}\mathrm{Fr} \\
{[-]}\end{array}$ & $\begin{array}{l}\text { Type } \\
* * *\end{array}$ & $\begin{array}{l}\alpha_{\text {lee }} \\
{\left[{ }^{\circ}\right]}\end{array}$ & $\begin{array}{l}H_{d} \\
{[\mathrm{~m}]}\end{array}$ & $\begin{array}{l}H_{b} \\
{[\mathrm{~m}]}\end{array}$ & $\begin{array}{l}\lambda \\
{[\mathrm{m}]}\end{array}$ & $\begin{array}{l}H_{d} / \lambda \\
{[-]}\end{array}$ & $\begin{array}{l}H_{r e l} \\
{[-]}\end{array}$ \\
\hline Kola & 1.50 & 0.68 & 0.59 & 1.6 & 0.23 & 1 & -30.0 & 0.15 & 0.10 & 3.75 & 0.04 & 0.18 \\
\hline Kolb & 1.50 & 0.66 & 0.81 & 3.6 & 0.32 & 1 & -30.0 & 0.15 & 0.10 & 3.75 & 0.04 & 0.18 \\
\hline $\mathrm{Ko} 2 \mathrm{a}$ & 1.50 & 0.68 & 0.66 & 2.9 & 0.26 & 1 & -30.2 & 0.15 & 0.13 & 3.75 & 0.04 & 0.18 \\
\hline Ko2b & 1.50 & 0.67 & 0.66 & 5.5 & 0.26 & 1 & -30.2 & 0.15 & 0.13 & 3.75 & 0.04 & 0.18 \\
\hline Ko3a & 1.50 & 0.68 & 0.67 & 4 & 0.26 & 1 & -30.0 & 0.15 & 0.15 & 3.75 & 0.04 & 0.18 \\
\hline Ko3b & 1.50 & 0.67 & 0.66 & 7.4 & 0.26 & 1 & -30.0 & 0.15 & 0.15 & 3.75 & 0.04 & 0.18 \\
\hline BB1 & 0.30 & 0.10 & 0.57 & $\mathrm{n} / \mathrm{a}$ & 0.58 & 2 & -31.0 & 0.05 & 0.03 & 0.67 & 0.07 & 0.31 \\
\hline MR5 & 1.50 & 0.25 & 0.44 & 9.6 & 0.28 & 1 & -25.3 & 0.08 & 0.08 & 1.60 & 0.05 & 0.28 \\
\hline MR6 & 1.50 & 0.33 & 0.55 & 9.5 & 0.30 & 1 & -25.3 & 0.08 & 0.08 & 1.60 & 0.05 & 0.22 \\
\hline ML2 & 0.90 & 0.16 & 0.39 & 9.5 & 0.31 & 1 & -29.7 & 0.04 & 0.04 & 0.81 & 0.05 & 0.23 \\
\hline ML3 & 0.90 & 0.55 & 0.28 & 0.82 & 0.12 & 1 & -29.7 & 0.04 & 0.04 & 0.81 & 0.05 & 0.07 \\
\hline ML4 & 0.90 & 0.16 & 0.38 & 12.2 & 0.30 & 1 & -29.8 & 0.04 & 0.04 & 0.41 & 0.10 & 0.22 \\
\hline ML5 & 0.90 & 0.16 & 0.20 & 3.6 & 0.16 & 1 & -29.7 & 0.04 & 0.04 & 0.41 & 0.10 & 0.22 \\
\hline ML6 & 0.90 & 0.30 & 0.54 & 10.2 & 0.31 & 1 & -29.8 & 0.04 & 0.04 & 0.41 & 0.10 & 0.12 \\
\hline ML7 & 0.90 & 0.56 & 0.24 & 0.9 & 0.10 & 1 & -29.8 & 0.04 & 0.04 & 0.41 & 0.10 & 0.07 \\
\hline Te1 & 0.50 & 0.23 & 0.50 & 4.75 & 0.33 & 1 & -38.2 & 0.06 & 0.06 & 0.50 & 0.13 & 0.30 \\
\hline $\mathrm{Te} 2$ & 0.50 & 0.23 & 0.50 & 4.75 & 0.33 & 1 & -38.2 & 0.06 & 0.06 & 0.50 & 0.13 & 0.30 \\
\hline NN1 & 0.30 & 0.06 & 0.14 & $\mathrm{n} / \mathrm{a}$ & 0.19 & 3 & -90.0 & 0.02 & 0.02 & $\mathrm{n} / \mathrm{a}$ & $\mathrm{n} / \mathrm{a}$ & 0.34 \\
\hline NN3 & 0.30 & 0.11 & 0.22 & $\mathrm{n} / \mathrm{a}$ & 0.22 & 3 & -90.0 & 0.02 & 0.02 & $\mathrm{n} / \mathrm{a}$ & $\mathrm{n} / \mathrm{a}$ & 0.19 \\
\hline $\mathrm{Ne} 1$ & 0.70 & 0.20 & 0.51 & $\mathrm{n} / \mathrm{a}$ & 0.37 & 1 & -29.7 & 0.04 & 0.04 & 0.80 & 0.05 & 0.21 \\
\hline Bu1 & 0.61 & 0.05 & 0.51 & $\mathrm{n} / \mathrm{a}$ & 0.75 & 4 & -31.7 & 0.01 & 0.01 & 0.05 & 0.20 & 0.19 \\
\hline Ra1 & 0.50 & 1.19 & 1.31 & $\mathrm{n} / \mathrm{a}$ & 0.38 & 3 & -90.0 & 0.91 & 0.91 & $\mathrm{n} / \mathrm{a}$ & $\mathrm{n} / \mathrm{a}$ & 0.44 \\
\hline
\end{tabular}

* Ko: Kornman (1995); BB: Bennett and Best (1955); MR: Van Mierlo and De Ruiter (1988); ML: McLean et al. (1999); Te: Termes (1984); NN: Nakagawa and Nezu (1987); N: Nelson et al. (1993); Bu: Buckles et al. (1984); Ra: Raudkivi (1963). ** $\mathrm{fw}=$ flume width; $\mathrm{H}=$ average waterdepth; $\mathrm{U}=$ average flow velocity; $S_{e}=$ energy slope; $\alpha_{\text {lee }}=$ angle lee-side (at separation point); $H_{d}=$ bedform height; $H_{b}=$ brinkpoint height; $\lambda=$ bedform length; $H_{r e l}=$ bedform height relative to waterdepth. *** Bedform types: $1=$ triangular dune; $2=$ solid dune; $3=$ backward step; $4=$ sinuous dune. 
characteristics. This should imply a value for $\gamma$ in the range between 5.1 and 6.3. However, in Figure 11 it can be observed that the value of $\gamma$ has a larger range.

In their aeolian dune development model, Kroy et al. (2002) use a value of 6 for $\gamma$ (which they state is known from many numerical calculations at high Reynolds numbers). Niño et al. (2002) use a value of $-14^{\circ}$ as angle for the (linear) zero velocity line, implying a value of 4 for $\gamma$. Parsons et al. (2004) have shown with numerical computations for flow over aeolian dunes, that, in general, the length of the separation zone varied from 3 to 15 times the dune height and increased over taller, steeper dunes.

Figure 12 shows the relation between the local bed angle at the brinkpoint of the dune $\left(\alpha_{b}\right.$, Fig. 10) and the total length of the flow separation zone $\left(L_{s t}\right)$. There

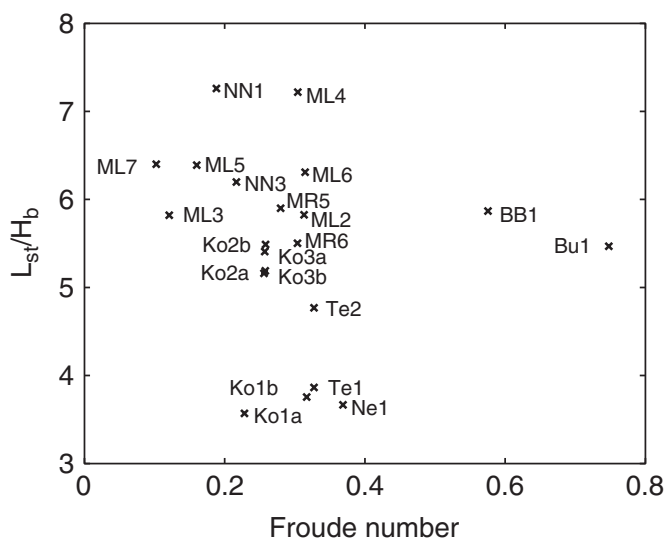

Figure 11. Dependency of the length of the flow separation zone on the Froude number.

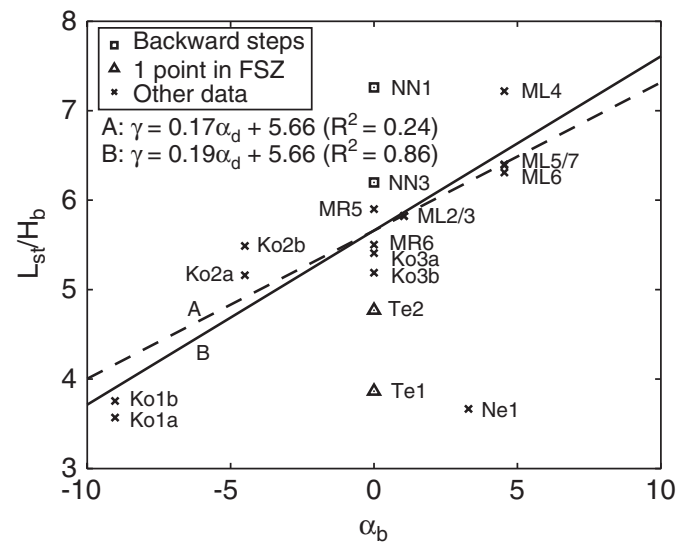

Figure 12. Relation between the total length of the flow separation zone and the local bed slope at the brinkpoint of the dune. BB1 and Bu1 are excluded from the plot, since no clear brinkpoint is present in those experiments. seems to be a clear relation between the variables. The length of the separation zone increases for increasing bed angle at the separation point. In Figure 12, line " $A$ " represents a linear regression function through all shown data. In line "B" the data of Termes (1984) and Nelson et al. (1993) are excluded. This is either due to few measurement points in the flow separation zone (the former), or due to inaccurate data (the latter). Backward steps are also excluded from this regression, since we are mostly interested in the behaviour over triangular shaped (asymmetric) bedforms. It is surprising that both regression functions are almost the same, but line "B" has a much higher coefficient of determination. We find the following function for estimating the length of the flow separation zone, when the brinkpoint and the local bed angle at this point are known:

$\gamma=L_{s t} / H_{b}=0.19 \alpha_{d}+5.66$

In short, it is shown that the length of the flow separation zone is indeed independent of general flow conditions as shown by Wilbers (2004). Further, a relationship is found between the length of the flow separation zone, and the local bed angle at brinkpoint. For larger bed angles at this point, the flow separation zone extends further downstream. In the following sections, the separating streamline is determined and parameterized. To estimate the flow separation zone length, the ratio $\gamma$ derived in this section is used to compute the flow reattachment point.

\subsection{Determination of the separating streamline}

For most experimental data from Table 2, profiles of horizontal velocities are available extending from the bed to the water surface, which are averaged over typical turbulent timescales (see e.g. McLean et al. 1999). Unfortunately, only flume data were detailed enough to use for the parameterization, requiring details of the velocity profile in the flow separation zone.

Because a recirculation eddy is present in the flow separation zone it is assumed that, in the flow separation zone, at each location along the bed the net discharge trough a vertical cross-section is zero (i.e. there is an equal discharge above and under the point of zero velocity). Based on this assumption, the height of the separating streamline $\left(z_{\text {sep }}\right.$, the $z$-coordinate of circled points in Fig. 9) is found from:

$\int_{z_{b}}^{z_{s e p}} u d z=0$

where $z$ is the height from the bottom $z_{b}$. Flow velocity at the bed is assumed to be zero, and the available velocity measurements are linearly interpolated. 
A different approach is to assume that above the flow separation zone, the discharge is equal to the specific discharge at the separation point:

$\int_{z_{\text {sep }}}^{z_{s}} u d z=q_{s}$
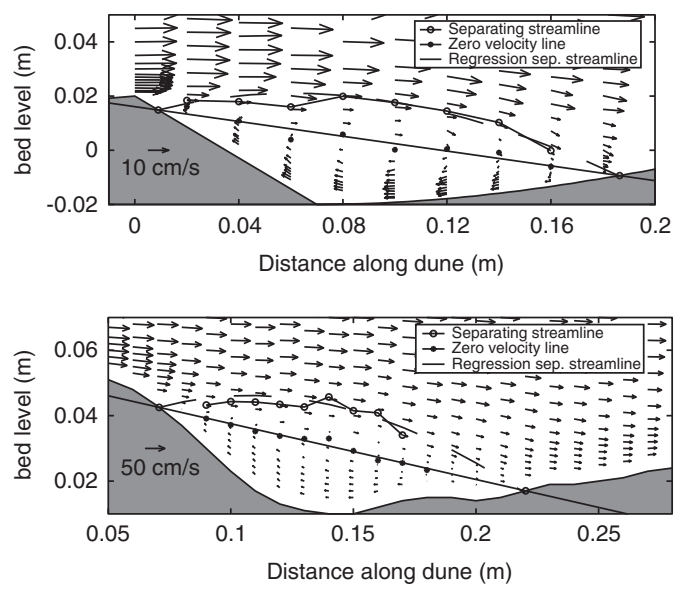

Figure 13. Computed points of separating streamline and regression through this line for experiment ML5 (top) and BB1 (bottom). where $z_{\text {sep }}$ is the unknown variable, $z_{s}$ is the level of the water surface, and $q_{s}$ is the specific discharge $\left[\mathrm{m}^{2} / \mathrm{s}\right]$ at the flow separation point.

Applying this formula to the data does not seem to work very well. This may be explained by the fact that towards the surface less measurements are available and for some experiments the water surface level is not known. The method using Equation (18) needs an accurate computation of specific discharge at the separation point. Small deviations in the computed discharge can result in a large deviation from the separating streamline, since near to the flow separation zone, velocities are smaller than towards the surface. Equation (17) does not require a computation of the specific discharge and can be applied directly. This equation is used in the analysis presented here. The computated points on the separating streamline for two flume experiments are shown in Figure 13, and the flow separation zone characteristics for other flume experiments are shown in Table 3. In the figure, the zero velocity line is included, giving the flow separationand reattachment point.

Figure 13 shows that the position where the flow separates $\left(x_{s}\right)$ does not necessarily coincide with the brinkpoint. Apparently, the flow needs some distance to separate from the bed. In Table 3, the parameter $\beta$ gives the ratio between the location of the separation point along the dune and the total length of the flow

Table 3. Separation zone characteristics.

\begin{tabular}{|c|c|c|c|c|c|c|c|c|c|c|c|}
\hline \multirow{2}{*}{$\begin{array}{l}\text { Author } \\
\text { Parameter ** }\end{array}$} & \multicolumn{6}{|c|}{ I. Zero velocity line and FSZ dimensions } & \multicolumn{5}{|c|}{ II. Separating streamline } \\
\hline & $\begin{array}{l}\alpha_{z v l} \\
{\left[{ }^{\circ}\right]}\end{array}$ & $\begin{array}{l}\beta \\
{[-]}\end{array}$ & $\begin{array}{l}H_{s} \\
{[\mathrm{~mm}]}\end{array}$ & $\begin{array}{l}L_{s} \\
{[-]}\end{array}$ & $\begin{array}{l}L_{s t} \\
{[\mathrm{~m}]}\end{array}$ & $\begin{array}{l}\gamma \\
{[-]}\end{array}$ & $\begin{array}{l}\alpha_{b} \\
{\left[{ }^{\circ}\right]}\end{array}$ & $\begin{array}{l}\alpha_{s} \\
{\left[{ }^{\circ}\right]}\end{array}$ & $\begin{array}{l}\alpha_{s}^{\prime} \\
{\left[^{\circ}\right]}\end{array}$ & $\begin{array}{l}\alpha_{r} \\
{\left[{ }^{\circ}\right]}\end{array}$ & $\begin{array}{l}\alpha_{r b} \\
{\left[{ }^{\circ}\right]}\end{array}$ \\
\hline Kola & -11.25 & 0.14 & 69.6 & 0.31 & 0.35 & 3.57 & -9.03 & -18.71 & 7.46 & -22.08 & 2.62 \\
\hline Kolb & -11.13 & 0.12 & 72.4 & 0.32 & 0.37 & 3.75 & -9.03 & -18.83 & 7.71 & -21.69 & 2.62 \\
\hline $\mathrm{Ko} 2 \mathrm{a}$ & -8.35 & 0.09 & 97.0 & 0.54 & 0.66 & 5.16 & -4.50 & -21.84 & 13.48 & -18.80 & 2.64 \\
\hline $\mathrm{Ko} 2 \mathrm{~b}$ & -9.69 & 0.02 & 120.0 & 0.60 & 0.70 & 5.49 & -4.50 & -20.50 & 10.80 & -20.88 & 2.64 \\
\hline Ko3a & -9.28 & 0.04 & 132.6 & 0.68 & 0.81 & 5.41 & 0.00 & -20.70 & 11.41 & -15.34 & 2.46 \\
\hline Ko3b & -9.40 & 0.05 & 128.9 & 0.66 & 0.78 & 5.19 & 0.00 & -20.58 & 11.17 & -21.76 & 2.65 \\
\hline BB1 & -9.67 & 0.00 & 32.5 & 0.15 & 0.19 & 5.87 & $11.62 *$ & -21.29 & 11.62 & -26.30 & 11.32 \\
\hline MR5 & -9.21 & 0.02 & 79.0 & 0.45 & 0.49 & 5.90 & 0.00 & -16.04 & 6.84 & -23.69 & 5.09 \\
\hline MR6 & -8.73 & 0.06 & 69.8 & 0.42 & 0.45 & 5.51 & 0.00 & -16.52 & 7.79 & -21.23 & 5.09 \\
\hline ML2 & -8.86 & 0.03 & 36.3 & 0.21 & 0.23 & 5.83 & 1.04 & -20.89 & 12.04 & -19.26 & 2.96 \\
\hline ML3 & -8.74 & 0.03 & 35.8 & 0.21 & 0.23 & 5.82 & 1.04 & -21.01 & 12.27 & -14.99 & 2.96 \\
\hline ML4 & -5.91 & 0.09 & 29.9 & 0.18 & 0.29 & 7.23 & 4.54 & -23.86 & 17.95 & -22.85 & 10.57 \\
\hline ML5 & -7.78 & 0.05 & 34.9 & 0.18 & 0.26 & 6.38 & 4.54 & -21.95 & 14.18 & -24.18 & 10.57 \\
\hline ML6 & -6.82 & 0.09 & 30.2 & 0.17 & 0.25 & 6.31 & 4.54 & -22.95 & 16.12 & -24.34 & 8.25 \\
\hline ML7 & -6.95 & 0.08 & 31.2 & 0.17 & 0.26 & 6.41 & 4.54 & -22.82 & 15.87 & -24.04 & 7.13 \\
\hline Te1 & -10.38 & 0.09 & 44.6 & 0.24 & 0.24 & 3.86 & 0.00 & -27.84 & 17.45 & -9.03 & 0.00 \\
\hline $\mathrm{Te} 2$ & -8.69 & 0.07 & 45.9 & 0.30 & 0.30 & 4.77 & 0.00 & -29.53 & 20.85 & -19.84 & 0.00 \\
\hline NN1 & -7.46 & 0.00 & 19.0 & 0.15 & 0.15 & 7.25 & $\mathrm{n} / \mathrm{a}$ & $\mathrm{n} / \mathrm{a}$ & 0.00 & -15.64 & 0.00 \\
\hline NN3 & -7.90 & 0.00 & 17.2 & 0.12 & 0.12 & 6.20 & $\mathrm{n} / \mathrm{a}$ & $\mathrm{n} / \mathrm{a}$ & 0.00 & -17.40 & 0.00 \\
\hline $\mathrm{Ne} 1$ & -11.19 & 0.12 & 29.0 & 0.14 & 0.15 & 3.67 & 3.29 & -18.56 & 7.37 & -26.90 & 2.15 \\
\hline Bu1 & -10.36 & 0.00 & 6.5 & 0.02 & 0.04 & 5.49 & $10.99 *$ & -21.36 & 10.99 & -28.07 & 29.14 \\
\hline Ra1 & -6.15 & 0.00 & 878.8 & 8.16 & 8.16 & 8.92 & $\mathrm{n} / \mathrm{a}$ & $\mathrm{n} / \mathrm{a}$ & 0.00 & -14.69 & 0.00 \\
\hline
\end{tabular}

* Brinkpoint assumed; ** See Figure 10 for definitions of angles, and $\gamma=L_{s t} / H_{b} ; \beta=x_{s} /\left(x_{s}+L_{s}\right)$. 
separation zone. The ratio is a measure for the relative distance of the separation point from the top of the dune; when this ratio is small, the point of flow separation is just after the bedform top. In cases where no clearly defined brinkpoint is present (BB1 and Bu1) the flow separates at the point where the angle of the lee-side is about $-31^{\circ}$ (see Table 2 ).

In performing regression to compute the separating streamline, the points of flow separation- and reattachment are included in the regression (Fig. 13). The separating streamline is not fitted through the brinkpoint, although this is expected to be flow separation point. It is observed that the angle of the separating streamline at the separation point shows symmetry with respect to the zero velocity line: $\alpha_{s}^{\prime}=\alpha_{s}-\alpha_{z v l}$ (Fig. 10). The results of the separating streamline found from regression using this approach, are included in Figure 13 for two of the experiments. When the regression line is known, the angle at which the separating streamline reattaches at the bed $\left(\alpha_{r}\right)$ can be computed. The results are included in Table 3.

\subsection{Parameterization of the separating streamline}

We want to find a parameterization for the separating streamline such that the new bed level connects smoothly at the flow separation point. Further, it was found in the previous section that the separating streamline reattaches on the stoss side of the next dune at a certain angle. This gives us the following regression function for the separating streamline $s(x)$ :

$$
\begin{array}{r}
s(x)=s_{3}\left(x-x_{s}\right)^{3}+s_{2}\left(x-x_{s}\right)^{2} \\
+s_{1}\left(x-x_{s}\right)+s_{0}
\end{array}
$$

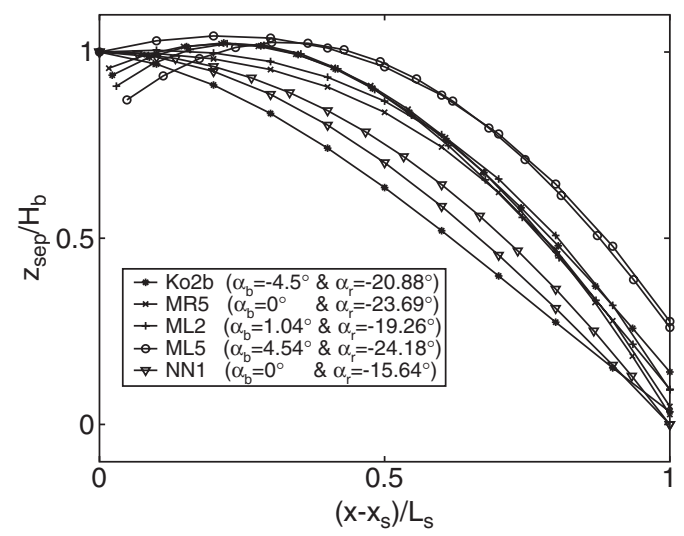

Figure 14. Parameterization of the separating streamline. Dashed lines are the regression functions based on the data. Solid line represent the parameterization for the same tests. where $x$ is the streamwise coordinate along the dune, and $x_{s}$ is the $x$-location of separation point. The coefficients $s_{0}$ and $s_{1}$ can are determined using characteristics at the flow separation point, which is assumed to be at the brinkpoint $\left(x=x_{b}\right)$ :

- $s_{0}=s\left(x_{s}\right)=H_{b}$ (bed level at $\left.x_{b}\right)$, and

- $s_{1}=s^{\prime}\left(x_{s}\right)=\alpha_{b}$ (local bed slope at $\left.x_{b}\right)$

The total length of the flow separation zone $\left(L_{s t}\right)$ can be estimated independent of flow conditions, using Equation (16). The reattachment point can then be found as the crossing-point between the bed and the zero velocity line (Fig. 10). We impose a constant angle of the separating streamline at the reattachment point $\left(x=x_{r}\right)$ :

- $s\left(x_{r}\right)=H_{r}$ (bed level at $\left.x_{r}\right)$, and

- $s^{\prime}\left(x_{r}\right)=\alpha_{r}\left(\right.$ angle of $s(x)$ at $\left.x_{r}\right)$

This is a main difference from the method of Kroy et al. (2002); they assumed smooth connection at the reattachment point on the flat bottom behind a dune. Using the conditions at the reattachment point gives:

$s_{2}=-3 \frac{H_{s e p}}{x_{r}^{2}}-\frac{\left(\alpha_{s e p}+\alpha_{b}\right)}{x_{r}}$

$s_{3}=2 \frac{H_{s e p}}{x_{r}{ }^{3}}+\frac{\alpha_{s e p}}{x_{r}{ }^{2}}$

where $H_{\text {sep }}=\left(H_{b}-H_{r}\right)$ and $\alpha_{\text {sep }}=\left(\alpha_{b}+\alpha_{r}\right)$.

Figure 14 shows the comparison of the separating streamlines computed from regression (see Section 5.3), and those found with the parameterization presented here, for five of the analyzed flume experiments. In the parameterization we use: $\alpha_{r}=-25^{\circ}$ for dunes, and $\alpha_{r}=-16^{\circ}$ for backward facing steps. The deviations near the separation point result from the determination of the separation point by extrapolating the zero velocity line to the bed (see e.g. Fig. 13a). However, Figure 14 shows that the parameterization still fits well to the data, especially towards the reattachment point. For experiments with a negative bed angle at the brinkpoint (experiments of Kornman) the parameterization fits the data to a lesser extent.

\section{CONCLUSIONS}

A morphodynamic model, originally developed for the simulation of offshore sand waves, is successfully recalibrated to use it for the simulation of river dunes (under steady flume conditions). An initial solitary sine-shaped bed disturbance grows in amplitude, 
develops into an asymmetric feature and migrates. Results are shown to be in agreement with linear stability analysis and with flume and river measurements.

Since flow separation cannot be treated explicitly in the model, a parameterization for flow separation is proposed. Thereto, the separating streamline is parameterized, using a relationship between the length of the flow separation zone and the local bed slope at the flow separation point. The separating streamline connects smoothly at the separation point, and it is assumed that the angle of the separating streamline at the reattachment point can be taken as a constant value of $-25^{\circ}$ for dunes. The parameterization is in reasonable agreement with data of flow over various types of bedforms with different characteristics.

Future work involves including this parameterization in a new numerical method based on the model equations described in this paper (Van den Berg and Van Damme 2005). In addition, a parameterization of sediment transport in the flow separation zone will be developed. Results of the dune development model, such as bedform height and length, and dimensions of the flow separation zone can be used to estimate the roughness caused by dunes. This information can be used in hydraulic models, to improve water level predictions during floods.

\section{ACKNOWLEDGEMENTS}

This work is supported by the Technology Foundation STW, the applied science division of NWO and the technology programme of the Ministry of Economic Affairs (Project No. TCB.6222). We would like to thank Ruud van Damme and Joris van den Berg for their help and support on the linear stability analysis and numerical model simulations. We are also grateful for the data provided by Antoine Wilbers and Prof. Steve McLean.

\section{REFERENCES}

Allen, J. R. L. (1976). Computational models for dune time-lag: general ideas, difficulties and early results. Sedimentary Geology 15, 1-53.

Bennett, S. J. and J. L. Best (1995). Mean flow and turbulence structure over fixed, two-dimensional dunes: implications for sediment transport and bedform stability. Sedimentology 42(3), 491-513.

Besio, G., P. Blondeaux, and P. Frisina (2003). A note on tidally generated sand waves. Journal of Fluid Mechanics $485,171-190$

Blom, A. and G. Parker (2004). Vertical sorting and the morphodynamics of bed form-dominated rivers: A modeling framework. Journal of Geophysical Research 109(F02007). 15 pp.
Buckles, J., T. J. Hanratty, and R. J. Adrian (1984). Turbulent flow over large-amplitude wavy surfaces. Journal of Fluid Mechanics 140, 27-44.

Chang, P. K. (1970). Separation of flow. Oxford: Pergamon Press.

Fredsøe, J. (1979). Unsteady flow in straight alluvial streams: modification of individual dunes. Journal of Fluid Mechanics 91, part 3, 497-512.

Hulscher, S. J. M. H. (1996). Tidal-induced large-scale regular bed form patterns in a three-dimensional shallow water model. Journal of Geophysical Research 101, 20727-20744.

Jansen, P. P., L. Van Bendegom, J. Van den Berg, M. De Vries, and A. Zanen (1994). Principles of river engineering, the non-tidal alluvial river. Delfste Uitgevers Maatschappij.

Julien, P. Y. and G. J. Klaassen (1995). Sand-dune geometry of large rivers during floods. Journal of Hydraulic Engineering 121(9), 657-663.

Julien, P. Y., G. J. Klaassen, W. B. M. Ten Brinke, and A. W. E. Wilbers (2002). Case Study: Bed resistance of Rhine River during 1998 flood. Journal of Hydraulic Engineering 128(12), 1042-1050.

Kennedy, J. F. (1969). The formation of sediment ripples, dunes and antidunes. Ann. Rev. Fluid Mech. 1, 147-168.

Komarova, N. L. and S. J. M. H. Hulscher (2000). Linear instability mechanics for sand wave formation. J. of Fluid Mechanics 413, 219-246.

Kornman, B. A. (1995). The effect of changes in the lee shape of dunes on the flow field, turbulence and hydraulic roughness. Report on measurements R 95-1, University of Utrecht, Utrecht, The Netherlands.

Kroy, K., G. Sauermann, and H. J. Herrmann (2002). Minimal model for aeolian sand dunes. Physical Review E 66(3).

Leliavsky, S. (1955). An Introduction to fluvial hydraulics. London: Constable.

McLean, S. R. and J. D. Smith (1986). A model for flow over two-dimensional bed forms. Journal of Hydraulic Engineering 112(4), 300-317.

McLean, S. R., S. R. Wolfe, and J. M. Nelson (1999). Spatially averaged flow over a wavy boundary revisited. Journal of Geophysical Research 104(C7), 15,743-15,753.

Nakagawa, H. and I. Nezu (1987). Experimental investigation on turbulent structure of backward-facing step flow in an open channel. Journal of Hydraulic Research 25, 67-88.

Nelson, J. M., S. R. McLean, and S. R. Wolfe (1993). Mean flow and turbulence fields over 2-dimensional bed forms. Water Resources Research 29(12), 3935-3953.

Nelson, J. M. and J. D. Smith (1989). Mechanics of flow over ripples and dunes. Journal of Geophysical Research 94(C6), 8146-8162.

Németh, A. A. (2003). Modelling offshore sand waves. Ph. D. thesis, University of Twente, Enschede, The Netherlands.

Németh, A. A., S. J. M. H. Hulscher, and H. J. De Vriend (2002). Modelling sand wave migration in shallow shelf seas. Continental Shelf Research 22, 2795-2806.

Niño, Y., A. Atala, M. Barahona, and D. Aracena (2002). Discrete particle model for analyzing bedform development. Journal of Hydraulic Engineering 128(4), 381-389.

Onda, S. and T. Hosoda (2004). Numerical simulation on development process of dunes and flow resistance. In M. Greco, A. Carravetta, and R. Della Morte (Eds.), 
Proceedings of River Flow 2004, Napoli, Italy, Volume 1, pp. 245-252. Frederico II University of Napoli: Balkema publishers, Leiden, the Netherlands.

Parsons, D. R., I. J. Walker, and G. F. S. Wiggs (2004). Numerical modelling of flow structures over idealized transverse aeolian dunes of varying geometry. Geomorphology 59, 149-164.

Raudkivi, A. J. (1963). Study of sediment ripple formation. Journal of the Hydraulics Division 89(6), 15-33.

Soulsby, R. L. (1990). Tidal-current boundary layers. In: The Sea, Vol. 9. Ocean Engineering Science, B. Le Mehaute and D. Hanes (eds.), pp. 523-566.

Stansby, P. K. and J. G. Zhou (1998). Shallow water flow solver with non-hydrostatic pressure: $2 \mathrm{D}$ vertical plane problems. International Journal of Numerical Methods in Fluids 28, 541-563.

Ten Brinke, W. B. M., A. W. E. Wilbers, and C. Wesseling (1999). Dune growth, decay and migration rates during a large-magnitude flood at a sand and mixed sand-gravel bed in the Dutch Rhine river system. Spec. Pub., Int. Assoc. Sediment. 28, 15-32.

Termes, A. P. P. (1984). Water movement over a horizontal bed and solitary sand dune. Rep. No. R/1984/H/8, Delft Univ. Tech., Delft, The Netherlands.

Van Damme, R. and J. Van den Berg (2005). Linear analysis steady flows. EWI, University of Twente (pers. comm.).

Van den Berg, J. and R. Van Damme (2005). Sand wave simulation on large domains. In G. Parker (Ed.), Proceedings of the 4th conference on River, Coastal and Estuarine Morphodynamics.

Van der Mark, C. F., A. Blom, S. J. M. H. Hulscher, S. F. Leclair, and D. Mohrig (2005). On modeling the variability of bedform dimensions. In G. Parker (Ed.), Proceedings of the 4th conference on River, Coastal and Estuarine Morphodynamics.

Van Mierlo, M. C. L. M. and J. C. C. De Ruiter (1988). Turbulence measurements above artificial dunes; Report on measurements. Report Q789, WL | Delft Hydraulics, Delft, The Netherlands.

Van Rijn, L. C. (1984). Sediment transport, part III: Bed forms and alluvial roughness. Journal of Hydraulic Engineering 110(12), 1733-1754.

Vanoni, V. A. and L. S. Hwang (1967). Relation between bed forms and friction in streams. Journal of the Hydraulic Division 93, 121-144.

Wijbenga, J. H. A. and A. R. Van Nes (1986). Flow resistance and bedform dimensions for varying flow conditions; results of flume experiments with flood waves. TOW rivieren R 567 - XXV/M 1314 part XIII, WL | Delft Hydraulics, Delft, The Netherlands.

Wilbers, A. (2004). The development and hydraulic roughness of river dunes. $\mathrm{Ph}$. D. thesis, University of Utrecht, Utrecht, The Netherlands.

Yoon, J. Y. and V. C. Patel (1996). Numerical model of turbulent flow over sand dune. Journal of Hydraulic Engineering 122(1), 10-18. 
